SHS Web of Conferences 6, 04003 (2014)

DOI: $10.1051 /$ shsconf / 20140604003

(C) Owned by the authors, published by EDP Sciences, 2014

\title{
Initiating New Prospects of Rural Science Popularization in the Digital Media Era
}

\author{
Li Jun ${ }^{\mathrm{a}}$ \\ College of Humanities, Zhejiang Shuren University, 310015 Hangzhou Zhejiang, China
}

\begin{abstract}
The development of digital media has brought a new challenge to existing science popularization in the rural areas. In this paper, new experience of rural science popularization on both traditional and digital media in Zhejiang province was introduced. We proposed several strategies for rural science popularization in the digital media era: First, we should strengthen the utilization of traditional platforms such as print media and broadcast and TV media. Then, digital media based on Internet should also be used for science popularization. Last but not least, we should also try to use "the fifth media" to upgrade existing platforms and create new Internet media channels.
\end{abstract}

Keywords. digital media; rural science popularization; new strategies

\section{The significance and focus of rural science popularization}

"Three issues concerning agriculture, countryside and farmers" are the key problems in the building of well-off countryside, the core of such questions is the agricultural efficiency. The disseminate of new technologies, new ideas and culture about new socialist countryside construction should depend on the popular science work. Humanistic Spirit, atmosphere of public opinion and social environment should be promoted and created by the media. Therefore, we must to have a thorough understanding about the construction of the new socialist countryside. It is necessary to enhance greatly the propaganda of science popularization in rural areas.

Rural science popularization is focused on universal, convenient and practical information service in this new era. Recently, local authorities in Zhejiang have tried to issue a series of policies aimed at rural science popularization work, having gained a lot of valuable experience, then spread the experience step by step and expanded the work in waves. Rural science popularization work includes such two sides: giving full play to the important role of traditional media, and actively exploring digital media outreach capabilities.

\section{Strengthening of the traditional media}

For decades, science propaganda in rural areas relies primarily on two measures. One is the print media, including newspapers, periodicals, books, and posters and so on, which is the important way to spread scientific thinking, advocate scientific methods, carry forward the scientific spirit, popularize scientific knowledge to improve the quality of public science and culture.[1] On July 1, 1964, the Zhejiang Sci-

\footnotetext{
${ }^{a}$ Corresponding author: zjlijun@163.com
} 
ence and Technology was published. It is a professional newspaper about popular science construction, to promote the scientific spirit and popularize scientific knowledge, which has a circulation of more than 200,000, and has been deeply welcomed by readers of the urban and rural areas. Readers construe it as "the golden key to get rich". Beginning since the 1980's, popular science construction of county newspapers is the forefront of China. On June 15, 1981, the Jinhua Popular Science was launched. Then, many kinds of Popular Science journals were also published in Zhejiang. As newspapers content were getting closer to local farmers, newspapers had a broader impact in rural areas, and the propaganda effect has been better.

On the other hand, there is the transmission of audiovisual media, including radio, television, film and so on. Public scientific literacy survey of the China Association for Science and Technology shows that television has been one of the largest channels accessing to scientific information in recent years. The Radio Film and Television Production Centre for Science Education is Zhejiang Provincial Science education institution, taking science education, publishing and technology promotion responsibilities, with 200 square meters, the virtual studio, a lot of video and audio equipments. Aimed to improve the scientific quality of the people, its mainly interview partners are academicians and experts.

Two major issues about Science popularization in the countryside should be considered: firstly, the terminal should have a high degree of popularity, the second is more convenient operation. Demand for Zhejiang government has widely established electronic reading devices in urban and rural to improve the newspaper's ability to communicate and to enhance the digital transformation of radio and television.

\subsection{Establish electronic reading common facilities}

Traditional newspapers have two very important advantages. One is abundant resources, there are many sources of information, certainly distribution channels and lots of readers. The other is the credibility. However, its disadvantage is also clear, people cannot read without subscription. There are so many place in Zhejiang has established many electronic reading common facilities. It provides read free newspaper.

The Xiaoshan Daily office has began to establish many electronic reading common facilities at urban and rural since 2005. It occupied the propaganda position, led the mass reading, enhancing spiritual and cultural life of the people, promoting scientific and cultural knowledge.

In this period, Ningbo, Jinhua and Huzhou had also established a lot of electronic reading common facilities.

It is an available method to improve the rural science popularization capability.

\subsection{Founding of propaganda system model of paroxysmal public crisis}

Effects of popular science are unable to appear in a relatively short period, but its results will be better to spread related scientific knowledge in the process of paroxysmal public crisis and disaster relief than radio or TV programmers. We must firmly grasp chances to spread the science after the incident.

After the Wenchuan Earthquake, radio and TV were disseminating the relevant information and knowledge, let audiences accept numerous scientific knowledge, such as seismic exploration knowledge, maritime satellite phone and life instrument and so on. It shows that the most efficient communication must be in the process of public crisis emergency. Because scientific knowledge is closely related to the vital interests of the public and causes great concern and the most profound memories. We should attach importance to the golden opportunity of popular science propaganda to promote the healthy development of the situation. The Zhenhai PX Project triggered mass incidents in October 2012. After that, local authorities use various media, including newspaper, Internet, radio and TV, multi-dimensional communicated related scientific knowledge and government information. So the event was over soon. 


\section{Development of network digital media}

China Internet Network Information Center (CNNIC) released the 31st China Internet Development Status Report, showing the number of Chinese netizens has reached 564 million by the end of december 2012 , Internet penetration has reached $42.1 \%$. It provides an opportunity for leap - forward development of the popular science work in the countryside.

Since 2009, popular science in rural areas has closely followed the development of digital media, innovated methods of work in Zhejiang.

\subsection{Construct digital television broadcasting}

Because of the traditional radio and television is extensive and influential, it is necessary to take digital transformation of radio and television, and to improve the ability of popular science propaganda.

In recent years, "four in one digital agriculture" project that based on CATV network in Hangzhou "digital television services, rural information service, rural information service platform, broadband communications" have meet the requirements of information development in rural areas. Bring the low cost and full coverage, multifunctional development goals into truth.

Hangzhou "Digital agriculture" project started in 2009, 31 villages have implemented the "Digital agriculture" project by the end of 2009. The total number of users had exceeded 330,000 by 2010 , 974,000 by 2011 .

Conversion of digital cable television has been rapidly advanced in Zhejiang Province by the end of 2011, as the forefront in China. Hangzhou "Digital agriculture" Project broke the traditional pattern of rural informatization. It has a scientific meaning and played a great role for the rural popular science.

\subsection{Try using "the fifth media"}

The 31st China Internet Development Statistics Report shows that the number of Mobile internet users in China is 420 million at the end of December 2012, annual growth rate of $18.1 \%$. At the same time, amount of mobile internet users continues to improve from $69.3 \%$ to $74.5 \%$. Mobile has become the largest internet terminal.

Mobile newspapers, such as the mobile Web can be used anytime and anywhere, Mobile media has become an important way to spread among persons. It can be called the following newspapers, radio, television and the Internet "the fifth media". [2]

By the end of December 2012, more than 80 per cent in rural areas of Zhejiang Province is mobile users. Popularity of mobile phones in rural degrees higher than the computer, Mobile newspaper is simple, low cost, send quick, receive convenient, users may read it in fragmented time. It is more suitable for peasant to read. Issuing mobile newspaper is also a good way for Rural Science of science and technology.

The Mobile Newspaper of Zhejiang Science and Technology is the most professional mobile newspaper in Zhejiang Province, as a result of the cooperation between the Zhejiang Science and technology newspaper office and Zhejiang Mobile company, which including information technology, life discovery, healthy life, novelty agriculture.

\subsection{Develop a network platform of popular science}

The characteristic of network is interactivity and mass. The result indicated the application of network can heighten an effect for the popular science. [3] At present, rural areas in Zhejiang Province all launched Network. It is necessary to build a new popular science propaganda positions on the network. In Zhejiang countryside, a new generation of young farmers are growing up, chasing the tide, catching in Internet, mobile newspaper, microbloging. We should build the network platform of the popular science propaganda for them. The popular science propaganda relying on Internet, set up popular science 
website to promote scientific and technological knowledge for farmers.[4] In recent years, using microbloging to carry out the work of popular science are more popular.

On March 5, 2012, Zhejiang popular microbloging phalanx, the first provincial science based on Tencent microbloging twitter Square officially launched. It is led by Zhejiang Provincial Association of Science and Technology. As popular science Resources Co - Constructing and Sharing innovative ideas is creative and rich, microbloging twitter Square will provide more powerful impetus to improve the quality of popular science.

The successful building of microbloging phalanx in Zhejiang has brought enlightenment to the popular science work in the countryside.

However, network media is a "fast - food culture". Popular science work must be prevented from pursuing the so-called big effect on the content and presentation techniques, or some sweet wildness phenomena. It is possible to get better publicity for popular science propaganda platform with digital media only with a good brand and credibility.

\section{Conclusions and implications}

Digital Media provides a good platform to spread scientific knowledge. Rural popular science works splendidly in the digital media era in Zhejiang, it mainly caught two points: No. 1, make full use of traditional media, keep innovating and develop new mode; Secondly, seize the opportunity, create a more diversified forms of popular science communication applying websites, mobile phone and twitter. Through a variety of digital media to learn knowledge, people can really fell the strength and charm of popular science. Hope these experiences can provide a reference to the popular science, and to create a better future in Digital Media era.

\section{Acknowledgement}

Here, I would like to take this opportunity to extend my gratitude to all the local governments and agencies concerned in Zhejiang, for their support to my research and writing.

Funding: 2013 Zhejiang Philosophy and Social Science Planning of "the Zhijiang Youth Project" (GN:13ZJQN088YB).

\section{References}

1. Linjun Zhang. Science Popularization and the New Rural Construction--The Role of Popular Print Media in the Rural Propaganda [J]. China's Foreign Trade, pp.296 (Ch) ,2011.9.

2. Yun Xiao, Runqiang Wang, Ying Wang, Hongyu Bi. Research on the Development and Trend of Mobile Science Communication Industry[J]. Science Popularization, pp.90, 2011.2 (supplement).

3. Qin Wang. Changes in the Concept of Digital Popular Science[J]. Science Popularization, pp. 32-38(Ch), 2011.8.

4. Ye Shang, Kaili Liu. The Rethinking of Popular Sciences Propaganda in the Internet Age[J]. Modern Science, pp. 109(Ch), 2009.7.

5. Yuyue Ye. Microblogging Group is Playing an Important Role in Popular Sciences [N]. Zhejiang Daily. 2012.3.5(Ch).

6. 2012 University Student Volunteers Environmental Protection Popular Science Activity in Thousands of Villages Has Been Started[EB/OL].

Tencent Education(Ch). http://edu.qq.com/a/20120322/000378.htm 